\title{
Influence of the Curriculum Support Materials Procured Through Free Secondary Education Tuition Fund and Quality of Curriculum Implementation in Public Secondary Schools in Makueni County
}

\author{
Kaindi R. Mueni ${ }^{1} \quad$ Kimiti Richard Peter ${ }^{2} \mathrm{PhD} \quad \& \quad$ Gideon Kasivu ${ }^{3}, \mathrm{PhD}$ \\ 1.PhD Candidate, Machakos University \\ 2.Machakos University, Senior Lecturer, Department of Educational Management and Curriculum Studies \\ 3.South Eastern Kenya University, Lecturer, Department of Educational Administration and Planning
}

\begin{abstract}
The success of the curriculum implementation process is influenced by three major factors; teachers' competence, students' characteristics and quality of the curriculum support materials. The study examined the influence of curriculum support materials procured through FSETF on quality of curriculum implementation in public secondary schools in Makueni County. The study employed a mixed methods research design. The sampling matrix comprised of 38 principals, 210 For 4 class teachers and 346 Form four students. Three instruments were used to collect data; semi structured questionnaires, interview guides and observation checklist. Qualitative data was analysed using thematic analysis while the quantitative data was analyzed using both descriptive inferential analyses. Descriptive statistics consisted of frequencies and percentages while inferential statistics comprised of chi-square statistic which tested the association between the variables. The study found out that there were several problems associated with the curriculum support materials supplied to schools and in particular the textbooks. In addition, the results of the study showed that there is a significant relationship between the quality of curriculum support materials and the quality of the curriculum implementation process. In view of these findings, study recommends that the Ministry of Education should put in place water tight mechanism for vetting the curriculum support materials supplied to schools in order to ascertain high standards.
\end{abstract}

Keywords: Curriculum implementation, Curriculum support materials, and Quality

DOI: $10.7176 / \mathrm{JEP} / 10-32-09$

Publication date: November $30^{\text {th }} 2019$

\subsection{BACKGROUND TO THE STUDY}

Globally, the success of any curriculum implementation process is influenced by three key factors; subject specialists, learners and curriculum support materials (KNEC, 2013). Consequently, many governments and in particular in the developing world have invested profoundly in education, by ensuring that schools have adequate teaching and learning resources commonly known as curriculum support materials. This is supported by UNESCO (2018) which emphasizes that curriculum support materials are critical ingredients in the curriculum implementation process.

In Kenya, the problem of effective curriculum implementation has been documented in reports and studies in the last decade (World Bank, 2018). Some of the problems affecting the curriculum implementation process included; inadequate qualified human resource, lack of clear curriculum policies, inadequate textbooks among other curriculum support materials. In attempt to address these problems, the Government of Kenya appointed a commission of education; the Totally Integrated Quality Education and Training (TIQET) (1999). In order to address the problem associated with the curriculum support materials, the commission recommended the introduction of government subsidies in the provision of teaching and learning resources.

As a result of the recommendations of the TIQET commission and also in attempt to address the problem of lack of sufficient and acquisition of high quality curriculum support materials at the secondary school level, the Kenyan government introduced the Free Secondary Education Policy in 2008. When Launching the Free Secondary Education Programme, the third President of Kenya (Mwai Kibaki) noted:

"Access to secondary education alone is not sufficient to provide the quality skilled human resource necessary for our country's sustainable development... This can only be achieved by ensuring that the schools are properly equipped with highly qualified human resource and standard and enough teaching and learning resources" (Siringi, 2008).

However, the government's efforts to ensure successful implementation of Free Secondary Education and in particular the procurement of curriculum support materials was frustrated by myriad of challenges; corruption among the book suppliers, either under or over supply of books and delay in supply of curriculum support materials among others (TSC, 2008). Another challenge experienced in the implementation of the secondary schools' book policy was lack of several varieties and poorly developed teaching resources. In addition, there was poor monitoring of the principals' involvement in the procurement process. 
The commitment of Kenyan Governments in ensuring that all schools had sufficient curriculum support materials was further demonstrated in 2018 when the Ministry of Education spend Ksh. 3.9 billion and further took over the procurement and supply of textbooks to all public secondary schools. In this programme; the Free Secondary Education Tuition Fund, the government laid out guidelines/instructions on what Curriculum Support Materials to be procured. The curriculum support materials that are purchased using this fund include; textbooks, chalk, teacher reference materials, exercise books for the students, laboratory equipment, teaching/learning aid like the charts and cater for internal exams (MoE, 2018).

According to this scheme, each student is allocated a total of Ksh. 4792 per academic year. In addition, policy has given the Ministry of Education the mandate to directly supply textbooks to schools, which implies that secondary schools no longer get cash set for purchasing textbooks. The FSETF policy further stipulates that each student is entitled to receive six (6) core textbooks. Since the implementation of FSETF in 2018, several problems have also been reported among them the supply of poor quality textbooks. However, the impact of the shortcomings found in the curriculum support materials supplied and procured in schools under FSETF on the quality of curriculum implementation had not been explored.

\subsection{OVERVIEW OF THE RELATIONSHIP BETWEEN QUALITY OF CURRICULUM SUPPORT MATERIALS PROCURED THROUGH FSETF AND THE QUALITY OF CURRICULUM IMPLEMENTATION}

According to UN Standards on textbook development, the quality of a textbook is determined by the following eight variables: content coverage (scope and depth), appropriateness of language, sequencing of material, methodology, emerging issues, variety, exercises and testing, and artwork/illustration. Kira and Bukagire (2013) explored the perceptions of education stakeholders on the implications of textbook liberalization policy in Tanzania. The study emphasized the need for appropriate policies for textbook production and utilization including the activities of the technical component which needed to be synchronized with the educational requirements so that quality textbooks could be produced. The study concluded that stability on the quality depended substantially on the rate at which educational stakeholders involved in textbook production accessed the relevant knowledge and skills of aligning the relevant content and pedagogical knowledge with the intended curriculum.

The importance of the impact of quality curriculum support materials on students' performance cannot under estimated as reported by many studies (Atieno, 2014). Oates (2014) while focusing on the importance of textbooks noted that, quality textbooks were a product of curriculum development process and go together with quality teaching and learning. He argued that quality textbooks offer varied application of concepts and facilitated active participation of all learners guiding them on what they are learning about. The study also emphasized that textbooks as a curriculum support material must be durable, affordable and accessible. With all these mentioned qualities, the current study was necessary because it examined the quality of textbooks supplied by the government and other curriculum support materials acquired through Free Secondary Education Tuition Fund in public secondary schools in Makueni County, Kenya and how they affected learning as part of curriculum implementation.

Andambi and Kariuki (2013) carried a study on the criteria of selecting curriculum support materials by teachers in Bungoma County indicated that good performance of students in KCSE examinations were influenced by the relevance of curriculum materials selected by their teachers. The study also found out that when the selected materials were relevant, desired academic outcomes are obtained. In a similar study, Mbengei and Galloway (2009 had earlier noted several policy changes in the education sector on the development of the publishing industry in Kenya which has been accused of lowering the quality of textbooks used in both primary and secondary school levels in Kenya. Another report by the Kenya Institute of Education (2009) on government's summative evaluation of the primary school education curriculum also alleged that publishers were producing school textbooks with factual and editorial errors. In retrospect, the Kenya Publishing Association (KPA) reacted to the report by accusing KIE of 'sleeping on the job'. This significantly indicated that there were sub-standard books being produced by educational publishers for the school market, while the concerned authorities were at loggerheads with one another.

\subsection{RESEARCH DESIGN}

This research applied a mixed methods research design where both qualitative and quantitative methods. This design was chosen since it the relationship between the quality of curriculum support materials and the curriculum implementation process is best established by both descriptive and quantitative methods of analysis.

\subsection{TARGET POPULATION}

The target population for the study was 381 public secondary schools in Makueni County (MOE Makueni County, 2018). The subjects included principals, class teachers and Form 4 students. The three categories of 
respondents were chosen because they were well informed about the variables being investigated in this study. In addition, the school principals were in charge of procuring other curriculum support materials apart from textbooks which were supplied by the government through the Ministry of Education

\subsection{SAMPLING TECHNIQUES AND SAMPLE SIZE}

Stratified random sampling was used to select the schools for the study from all Sub-counties. The principals who participated in the interviews were sampled purposively. The form four class teachers and form four students who filled the questionnaires were selected using simple random sampling. The study was carried out in 38 schools from which 38 principals, 210 teachers and 346 students were selected yielding a total of 594respondents.

\subsection{DATA COLLECTION INSTRUMENTS}

The study used three research instruments; questionnaires, interview and observation schedules. The questionnaires consisted of both open and closed ended questions. The questionnaires were administered to class teacher and student respondents respectively

\subsection{RESULTS OF THE STUDY}

The study examined the quality of curriculum support materials procured through Free Secondary Education Tuition Fund and its effect on quality of curriculum implementation in public secondary schools in Makueni County. The quality of the curriculum support materials was measured by determining whether there were shortcomings/errors in such materials. The results about the errors found in textbooks are presented in Table 1. The findings as outlined in Table one showed that spelling errors was on the lead as identified by an overwhelming majority of the students, 290 (94.40\%). The results further revealed that $183(59.61 \%)$ students stated that repeated content was another shortcoming observed in these textbooks. The research also found that $73(23.78 \%)$ of the students highlighted blank pages as a shortcoming found, $112(36.48 \%)$ noted that the textbooks had invisible words while 54 (17.59\%) noted that content not rhyming with the topic was a shortcoming they had found in these textbooks. The findings implied that the quality of textbooks provided to students in public secondary schools was compromised.

The above observation thus questioned the efficiency of the Kenya Institute of Curriculum Development and the Ministry of Education in general in controlling the quality of textbooks supplied to schools. This was attributed to the fact that there were many approved textbooks with incoherent content, conceptual and grammatical errors and poor illustrations.

Table 1: Errors in the Textbooks Supplied to Public Secondary Schools

\begin{tabular}{lclc}
\hline Type of Error & Students & Type of Error & Class teachers \\
\hline Spelling problems & $290(94.46)$ & Spelling mistakes & $100(74.07)$ \\
Blank pages & $73(23.78)$ & Blank spaces/pages & $7(5.19)$ \\
Repeated content & $183(59.61)$ & Invisible words & $7(5.19)$ \\
Invisible words & $112(36.48)$ & Missing pages & $7(5.19)$ \\
$\begin{array}{l}\text { Content not rhyming with } \\
\text { the topic }\end{array}$ & $54(17.59)$ & Wrong labelling of diagrams & \\
& & Wrong use of symbols, formulas and & $35(25.93)$ \\
& & calculations & $21(15.56)$ \\
& Contradictory information/ statements on & $15(11.11)$ \\
& the same concept & $7(5.19)$ \\
& Very shallow content which needs to be & $8(5.93)$ \\
& & supplemented & $22(16.30)$ \\
\hline
\end{tabular}

\section{NB: Number parentheses are Percentages}

The findings as reported by the students were supported by those of the class teachers when $135(82.3 \%)$ reported that they had received complaints from their students regarding the quality of curriculum support materials used in their classes. Similarly, during the interviews, 22(71.0\%) principal interviewees also indicated that they had noticed errors in the textbooks supplied. The findings implied poor quality textbooks supplied to public secondary schools was a cause of stress for students which can be attributed to confusion they faced and compromised teaching more so given the fact that most mistakes identified touched on the content. The findings therefore implied that the internal stakeholders starting from the schools' principals were aware of the low quality of the textbooks supplied by the government.

The findings were in line with Oduor (2018) who observed that several errors had been detected in the textbooks supplied to secondary schools. Mahmood (2011) had also earlier noted that a large number of the 
textbooks that had been approved in public schools lacked several desirable characteristics. These deficiencies had been reported with respect to different characteristics of quality textbooks including, but not limited to, content coverage, scope of developing understanding, horizontal and vertical alignment in the text, and approaches to the delivery of textbooks. These findings revealed poor quality controls by the Kenya Institute of Curriculum Development during the vetting of textbooks and cases where publishers influenced the approval of flawed books as stated by the author.

The study also sought to find out whether the errors noted in the preceding section cuts across all the subjects in the secondary school curriculum. The subjects of the textbooks that had the aforementioned shortcomings were identified and the findings are outlined in Table 2.

Table 2: Subjects of the Textbooks Identified with the Mentioned Shortcomings

\begin{tabular}{|c|c|c|c|c|}
\hline \multicolumn{3}{|c|}{ Subjects of the Textbooks Identified with the Mentioned Shortcomings } & \multicolumn{2}{|c|}{$\begin{array}{l}\text { Number of Textbooks with } \\
\text { Mistakes }\end{array}$} \\
\hline Subject & No. of students & No. of principals & Response & $\begin{array}{l}\text { No. of class } \\
\text { teachers }\end{array}$ \\
\hline Kiswahili & $181(58.96)$ & $22(70.97)$ & None & $7(4.3)$ \\
\hline Mathematics & $129(42.02)$ & $19(61.29)$ & Quite a number & $101(61.6)$ \\
\hline Chemistry & $172(56.03)$ & $22(70.97)$ & Many & $56(34.1)$ \\
\hline Agriculture & $14(4.56)$ & $3(9.68)$ & Total & $164(100.0)$ \\
\hline Biology & $177(57.65)$ & $10(32.26)$ & & \\
\hline CRE & $15(4.89)$ & $3(9.68)$ & & \\
\hline History & $30(9.77)$ & & & \\
\hline Geography & $8(2.61)$ & & & \\
\hline Physics & $20(6.51)$ & $3(9.68)$ & & \\
\hline English & $14(4.56)$ & & & \\
\hline Computer studies & $5(1.63)$ & & & \\
\hline Business studies & $12(3.91)$ & & & \\
\hline French & $7(2.28)$ & & & \\
\hline Homescience & $1(0.33)$ & $\mathrm{N}=31$ & & $\mathrm{~N}=164$ \\
\hline
\end{tabular}

\section{NB: Number parentheses are Percentages}

As shown tin Table 2, most of the several errors were found in Kiswahili textbooks as indicated by 181 $(58.96 \%)$ students, followed by Biology textbooks with a frequency of $177(57.65 \%)$, Chemistry was third as reported by $172(56.03 \%)$ students and fourth was Mathematics textbooks as stated by $129(42.02 \%)$ of the students. Other subjects where textbooks had errors included Agriculture, CRE, History, Geography, Physics, English, Computer Studies, Business Studies, French and Homescience. Table 2 further shows that principals had noted errors majorly in Kiswahili and Chemistry with $70.97 \%$ and $61.29 \%$ respectively. Errors in Mathematics textbook were reported at $10(32.26 \%)$. The percentage of errors in other subjects is summarized in Table 2. It can therefore be deduced that errors had been detected in textbooks for almost all the subjects even though some of the subjects were more affected than others. The findings signify the magnitude of the challenge of poor quality in the government's free textbook programme.

The overall assessment of the quality of curriculum support materials available in classes by the class teachers and principals are presented in Table 3.

Table 3: Overall Assessment of the Quality of Curriculum Support Materials

\begin{tabular}{lcc}
\hline Rank & Teachers & Principals \\
\hline Poor & $8(4.9)$ & $10(32.30)$ \\
Fair & - & $21(67.70)$ \\
Good & $150(91.5)$ & - \\
Very good & $6(3.7)$ & - \\
Total & $164(100.0)$ & $31(100.00)$ \\
\hline
\end{tabular}

\section{NB: Number parentheses are Percentages}

It was found that majority of the class teachers, $150(91.5 \%)$, rated the quality of the curriculum support materials available as good. On the other hand, a majority of the principals, $21(67.70 \%)$, felt that the quality of these materials was fair while the rest, $10(32.3 \%)$ indicated that the quality was poor. These findings can be explained by the many mistakes identified in textbooks supplied by the government which brewed negative perceptions of the curriculum support materials channeled to schools. The findings also implied that the government had a long way to go in ensuring that quality of curriculum support materials was improved and that the negative perceptions on the quality of materials supplied among educational stakeholders were altered. During interviews with the principals, all the interviewees indicated that when purchasing curriculum support materials, they found various qualities of the curriculum support materials. In explaining, the principals indicated that some materials were of poor quality while others were of high quality, hence the principal had to specify 
what they wanted depending on the prices. Some of the principal verbative responses are summarized below; ..... "Yes, they are of different qualities. Some are of low quality and others high quality. The ones of high quality are more durable compared to the low quality items. They are readily available only that they are very expensive."

.... "Yes, lab materials are in various qualities. You have to specify depending on quality and price."

... "Yes, qualities differ. Some are of high quality, others low and even the content in some books is very shallow. Lab equipment are durable and others are fake."

The of results chi-square analysis showed that there was a significant association between student complaints regarding the quality of curriculum support materials and quality of curriculum implementation in public secondary schools under research given $\left(\chi^{2}=7.253, p=0.007, p<0.05\right)$. The findings supported the research by Atieno (2014) which noted that curriculum support materials ought to have high physical and technical quality that makes them appealing to the users. The findings were also in line with that of Oates (2014) who found that quality textbooks offered varied application of concepts and facilitated active participation of all learners guiding them on what they were learning about.

\subsection{CONCLUSIONS}

Based on these findings, the study concluded that there were numerous quality concerns regarding the curriculum support materials supplied by the government ranging from spelling mistakes, repeated content, invisible words, blank pages and content which did not rhyme with topic more so textbooks in all most all the subjects which affected the general quality of curriculum support materials available to schools.

\subsection{RECOMMENDATIONS}

In view of these findings, the study recommends that the Ministry of Education should vet the all materials supplied to schools by various publishers to ensure that there is high quality control as this adversely affect the curriculum implementation process. The study also recommends the Kenya Institute of Curriculum Development that should have in place established structures and frameworks to guarantee the quality of curriculum support materials developed by its officers.

\section{REFERENCES}

Andambi, R., \& Kariuki, B. (2013). Criteria for selecting relevant learning resources by teachers of social education and ethics in Bungoma District, Kenya. Journal of Emerging Trends in Educational Research and Policy Studies, 4(1), 133-140.

Atieno, A. J. (2014). Influence of teaching and learning resources on students' performance in Kenya certificate of secondary education in free day secondary Education in Embakasi district, Kenya. Unpublished Thesis, University of Nairobi.

Boser, U., Chingos, M. M., \& Straus, C. (2015). The hidden value of curriculum reform: Do states and districts receive the most bang for their curriculum buck? Retrieved from: https://www.americanprogress.org/issues/education-k-12/reports/2015/10/14/122810/the-hidden-value-ofcurriculum-reform/

Brock, S. E. (2013). Selecting a sample. Educational Research EDS 250

Chiriswa, P. (2002). An investigation into the probable factors responsible for poor performance in Kenya Certificate of Secondary Education (KCSE) in Vihiga District of Western Province, Kenya. MED Kenyatta University Kenya.

Guloba, M., Wokadala, J., \& Bategeka, L. (2010). Does teaching methods and availability of Teaching resources influence pupils' Performance: evidence from four Districts in Uganda (No. 677-2016-46673).

Kaswa, J. M. (2015). The effect of visual learning aids on student's academic performance in public secondary schools: A case of Magu District secondary schools (Doctoral dissertation, The Open University of Tanzania).

Kenya Institute of Education (KIE). (2009). Summative Evaluation of the Primary School Education Curriculum. Accessed on 4 September 2019 from http://www.kie.ac.ke/

Khamati, M. J., \& Nyongesa, W. J. (2013). Factors influencing implementation of free secondary education in Mumias District, Kenya. M. Ed Thesis Maasai Mara University.

Kira, E., \& Bukagire, G. (2013). Perceptions of education stakeholders on the implications of textbook liberalization policy in Tanzania. Journal of Education and Practice, 4(1), 136-143.

Kira, E., \& Bukagire, G. (2013). Perceptions of education stakeholders on the implications of textbook liberalization policy in Tanzania. Journal of Education and Practice, 4(1), 136-143.

KNEC (2013). Kenya Certificate of Secondary Education 2013 candidates' performance report Nairobi.

Krejcie, R. V., \& Morgan, D. W. (1970). Determining sample size for research activities. Educational and psychological measurement, 30(3), 607-610. 
Mahmood, K. (2010). Textbook evaluation in Pakistan: Issues of conformity to the national curriculum guidelines. Bulletin of Education and Research., 32(1), 15-36

Mahmood, K. (2011). Conformity to quality characteristics of textbooks: The illusion of textbook evaluation in Pakistan. Journal of research and Reflections in Education, 5(2), 170-190.

Mbengei, B., \& Galloway, F. (2009). The impact of policy changes in the education sector on the development of the book publishing industry in Kenya. Mousaion, 27(1), 159-174.

Mwandisi, S. (2016). The influence of teaching and learning materials on students' academic performance in secondary schools in Tanzania: A case of selected secondary schools in Mtwara Municipality. Unpublished research project, Tumaini University Makunira.

Mwiria, K. (1985). The Harambee school movement: A historical perspective. Unpublished Ph. D Thesis, University of Wisconsin.

Oates, T. (2014). Why textbooks frequency: A policy paper Cambridge: Cambridge Assessment, University of Cambridge.

Oduor, A. (2018, March, 18). Teachers reject new textbooks due to multiple errors. Standard Digital. Retrieved from: https:/www.standardmedia.co.ke/article/2001272355/shocking-errors-in-sh7-billion-textbooks

Rivkin, S. G., Hanushek, E. A., \& Kain, J. F. (2005). Teachers, schools, and academic achievement. Econometrica, 73(2), 417-458

Sigei, J. (2017, September, 22). Ministry's one-textbook policy kicks up a storm. Daily Nation. Retrieved from: https://www.nation.co.ke/news/education/Ministry-s-one-textbook-policy-kicks-up-a-storm/26436044108038-yo9anb/index.html

Swiniarski, L. B. (Ed.). (2013). World class initiatives and practices in early education: Moving forward in a global age (Vol. 9). Springer Science \& Business Media.

UNESCO (1993). Textbook development guidelines, viewed 9 July 2010, from http://www.unesco.org/en/textbook-development/guidelines/

World Bank (2011). Effect of eliminating school fees in developing countries. Government Press Nairobi. 